\title{
Photo-lability of deep ocean dissolved black carbon
}

\author{
A. Stubbins ${ }^{1}$, J. Niggemann ${ }^{2}$, and T. Dittmar ${ }^{2}$ \\ ${ }^{1}$ Skidaway Institute of Oceanography, Savannah, Georgia, 31411, USA \\ ${ }^{2}$ Max Planck Research Group for Marine Geochemistry, University of Oldenburg, \\ Institute for Chemistry and Biology of the Marine Environment, Carl-von-Ossietzky-Str. 9-11, \\ 26129 Oldenburg, Germany
}

Correspondence to: A. Stubbins (aron.stubbins@skio.usg.edu)

Received: 4 January 2012 - Published in Biogeosciences Discuss.: 16 January 2012

Revised: 29 March 2012 - Accepted: 2 April 2012 - Published: 9 May 2012

\begin{abstract}
Dissolved black carbon (DBC), defined here as condensed aromatics isolated from seawater via PPL solid phase extraction and quantified as benzenepolycarboxylic acid (BPCA) oxidation products, is a significant component of the oceanic dissolved organic carbon (DOC) pool. These condensed aromatics are widely distributed in the open ocean and appear to be tens of thousands of years old. As such DBC is regarded as highly refractory. In the current study, the photo-lability of DBC, DOC and coloured dissolved organic matter (CDOM; ultraviolet-visible absorbance) were determined over the course of a 28 day irradiation of North Atlantic Deep Water under a solar simulator. During the irradiation DBC fell from $1044 \pm 164 \mathrm{nM}-\mathrm{C}$ to $55 \pm 15 \mathrm{nM}$ C, a 20-fold decrease in concentration. Dissolved black carbon photo-degradation was more rapid and more extensive than for bulk CDOM and DOC. The concentration of DBC correlated with CDOM absorbance and the quality of DBC indicated by the ratios of different BPCAs correlated with CDOM absorbance spectral slope, suggesting the optical properties of CDOM may provide a proxy for both DBC concentrations and quality in natural waters. Further, the photo-lability of components of the DBC pool increased with their degree of aromatic condensation. These trends indicate that a continuum of compounds of varying photolability exists within the marine DOC pool. In this continuum, photo-lability scales with aromatic character, specifically the degree of condensation. Scaling the rapid photodegradation of DBC to rates of DOC photo-mineralisation for the global ocean leads to an estimated photo-chemical half-life for oceanic DBC of less than 800 years. This is more than an order of magnitude shorter than the apparent age of DBC in the ocean. Consequently, photo-degradation
\end{abstract}

is posited as the primary sink for oceanic $\mathrm{DBC}$ and the apparent survival of DBC molecules in the oceans for millennia appears to be facilitated not by their inherent inertness but by the rate at which they are cycled through the surface ocean's photic zone.

\section{Introduction}

Dissolved organic matter (DOM) plays a major role in key biogeochemical processes: providing sustenance at the base of microbial foodwebs; transporting carbon (C), nutrients and trace elements from the land to the oceans; and mediating fluxes of $\mathrm{C}$ from vegetation and soils, to rivers, the oceans, and eventually, the atmospheric $\mathrm{CO}_{2}$ pool. The DOM pool in the oceans represents one of the largest global C pools ( 700 Pg-C; Hansell, 2002), storing approximately the same amount of $\mathrm{C}$ as is found in all living organisms on Earth. Due to its great size, even minor changes in the dynamics of the DOM pool or its components can impact the global ecosystem, particularly ocean $\mathrm{C}$-storage and atmospheric $\mathrm{CO}_{2}$.

The DOM pool is of further interest as an information rich set of tracers, diverse in source, reactivity and history. These molecules carry the signatures of their source and subsequent journey through the environment to their point of analysis. The great potential of mining this information led Hedges (2002) to state that "the future of oceanographic research belongs in large part to those who can learn to read these molecular messages". This paper focuses upon one component signature within the DOM pool: dissolved black carbon. 
In the context of this study, dissolved black carbon (DBC) refers specifically to dissolved polycyclic aromatics. As far as is known, DBC can only be formed thermogenically, making it a specific tracer for thermally altered DOM (Dittmar, 2008). Heating of organic matter results in a number of reactions, including condensation reactions which yield polycyclic aromatics (alternatively referred to as polycyclic aromatic hydrocarbons and condensed aromatics in the literature). The benzenepolycarboxylic acid (BPCA) oxidation products of these condensed aromatics are identified and quantified as DBC (Dittmar, 2008). The parent molecules from which these BPCAs are derived are assumed to have molecular weights ranging from approximately 430 to 530 Daltons based upon the fraction detected by high resolution mass spectrometry (Dittmar and Koch, 2006).

Dissolved black carbon was recently found to occur throughout a number of major ocean water masses at concentrations between 600 and 810 nanomols of carbon per $\mathrm{L}$ (nM-C) or $\sim 2 \%$ of total dissolved organic carbon (DOC) (Dittmar and Paeng, 2009). This makes DBC one of the most prevalent of organic molecular classes quantified in the global ocean. By comparison lignin derived phenols, the oxidation products of aromatic compounds from terrestrial plants, occur at $<0.1 \%$ of total DOC (Opsahl and Benner, 1997; Hernes and Benner, 2006), total hydrolysable amino acids at $\leq 1.9 \%$, total hydrolysable neutral sugars at $\leq 4.5 \%$ and total hydrolysable amino sugars at $\leq 0.6 \%$ (Kaiser and Benner, 2009).

Dissolved black carbon has been observed in the abyssal ocean, leading to suggestions of a deep ocean source, possibly associated with heating at hydrothermal vents (Dittmar and Koch, 2006). Strong land-ocean concentration gradients (Mannino and Harvey, 2004; Dittmar 2008) also indicate that a terrestrial source for marine DBC exists and polycyclic aromatics have been identified in the high resolution mass spectra of Congo (Stubbins et al., 2010) and Amazon (Kim et al., 2004) river water. Jurado et al. (2008) report deposition of black carbon to the global ocean, though they do not quantify the condensed aromatics comprising the DBC pool specifically. The molecular signatures of DBC were also found to be elevated in glacier DOM derived from aerosol deposition (Stubbins et al., 2012). Therefore, deposition of combustion derived aerosols likely provides an additional source of DBC to the surface ocean. As a significant fraction of aerosols are formed through the burning of fossil fuels (Jurado et al., 2008), it is also likely that any DBC deposited to the ocean surface is radiocarbon depleted.

Black carbon is commonly described as refractory (e.g. Preston and Schmidt, 2006), an impression formed through observations of particulate black carbon's bioresistance and accumulation in soils and marine sediments (Druffel, 2004). Black carbon comprises a continuum of thermo-altered molecules from slightly altered biopolymers through highly condensed polycyclic aromatic compounds to graphitic carbon. Temperature plays a role in determining black carbon's chemistry, with chars produced at low temperature being less condensed and richer in polar functional groups than those produced at higher temperatures (Kuo et al., 2008; Keiluweit et al., 2010, Schneider et al., 2010). These variations in black carbon's molecular structure influence its reactivity and fate in the environment.

In the oceans, the high molecular weight fraction ( $>1000 \mathrm{Da}$ ) of DBC (condensed aromatics) was recently reported to have an apparent radiocarbon age of $18000 \pm 3000$ years before present (Ziolkowski and Druffel, 2010) making DBC the most ${ }^{14} \mathrm{C}$ depleted class of dissolved organic molecules identified as distributed throughout the oceans. The discovery that DBC is present at similar concentrations throughout the deep ocean (Dittmar and Paeng, 2009) also implies that it is highly recalcitrant. In contrast to this impression, all dissolved polycyclic aromatics identified in the Fourier transform ion cyclotron resonance mass spectra of Congo River water were lost after 57 days of irradiation under simulated sunlight (Stubbins et al., 2010). This result, as well as observations of depleted concentrations of DBC in ocean surface waters (Dittmar and Paeng, 2009) and the well documented photo-reactivity of other dissolved aromatic compounds (Vähätalo et al., 1999; Opsahl and Benner, 1998; Stubbins et al., 2008; Spencer et al., 2009) indicate that photo-degradation may be a significant sink for DBC in natural waters. Therefore, the presented work sought to determine the photo-labile fraction of DBC in deep seawater.

\section{Methods}

\subsection{Sample collection}

Bermuda Atlantic Time Series (BATS) cruise 252 on board the RV Atlantic Explorer (6th to 10th November 2009) was joined to collect North Atlantic Deep Water (NADW), one of the major global deep ocean water masses. The NADW sample was collected by CTD on 09/11/2009 from $3000 \mathrm{~m}$ at the BATS site $\left(31^{\circ} 40^{\prime} \mathrm{N}: 64^{\circ} 10^{\prime} \mathrm{W}\right)$. Three Niskin bottles were fired at $3000 \mathrm{~m}$. As soon as the CTD was on deck and secure, large surface area $0.2 \mu \mathrm{m}$ capsule filters were attached (Polycap TC, Whatman) directly to the Niskin bottles' nipples and sample was gravity filtered into a $20 \mathrm{~L}$ fluorinated high density polyethylene carboy (Nalgene). The filters and carboy were precleaned by soaking for at least $24 \mathrm{~h}$ in acidified ultrapure (MilliQ) water ( $\mathrm{pH} 2$ with hydrochloric acid; p.a.), soaking in basic ultrapure water for a further $24 \mathrm{~h}$ ( $0.1 \mathrm{M}$ sodium hydroxide; p.a.), and rinsing with copious volumes of ultrapure water (filters flushed with $>20 \mathrm{~L}$; carboy quintuple rinsed). The sample was then stored frozen in the dark at $-20^{\circ} \mathrm{C}$ onboard RV Atlantic Explorer until she docked in Norfolk, Virginia, USA (19/12/2009). At this point the carboy was collected and taken to Old Dominion University, approximately 10 minutes drive from the dock, and returned to $\mathrm{a}-20^{\circ} \mathrm{C}$ freezer. From there, the sample 
was later transported the nine hours to Skidaway Institute of Oceanography (SkIO), Georgia, USA in a large cooler with other frozen samples and placed back in a $-20^{\circ} \mathrm{C}$ freezer upon arrival. Thus, the sample remained frozen from shortly after collection until defrosting for the irradiation study.

\subsection{Irradiations}

On the 20th of September 2010 the thawed sample was transferred to six $2 \mathrm{~L}$ precombusted spherical quartz irradiation flasks. A further $4 \mathrm{~L}$ aliquot was divided between two $2 \mathrm{~L}$ combusted borosilicate flasks, which were then wrapped in aluminium foil. All samples were then placed under a solar simulator fitted with 12 UVA-340 bulbs (integrated irradiance $\sim 25 \mathrm{Wm}^{-2}$; Q-Panel), which provide a spectral shape and flux closely approximating natural sunlight from 295 to $365 \mathrm{~nm}$ (Stubbins et al., 2008), the main wavelength range for environmental photochemical reactions involving coloured dissolved organic matter (CDOM). The temperature in the solar simulator was kept at approximately $20^{\circ} \mathrm{C}$ using a side mounted fan. Sample water temperatures were likely higher as measured temperatures for test samples have been between $25^{\circ} \mathrm{C}$ and $30^{\circ} \mathrm{C}$. Duplicate $2 \mathrm{~L}$ flasks were taken from the light table after 2, 6 and 28 days. One day of irradiation using this solar simulator design is approximate to 1.27 times daily solar irradiance during the winter at $36.89^{\circ} \mathrm{N}$ or 0.67 times the daily $(12 \mathrm{~h})$ irradiance at the equator (Helms et al., 2008; Spencer et al., 2009).

\subsection{Ultraviolet-visible absorption spectra}

Following irradiation, $20 \mathrm{~mL}$ aliquots were transferred from the flasks to combusted glass vials, which were then capped with Teflon septa and placed in the dark for approximately $8 \mathrm{~h}$ in order to return to room temperature. Subsequently this aliquot was drawn through a $10 \mathrm{~cm}$ flow through quartz absorbance cell situated in the light path of an Agilent 8453 ultraviolet-visible spectrophotometer and sample CDOM absorbance spectra were recorded. An aliquot of ultrapure water (MilliQ) was run immediately before and after the sample and these two ultrapure water spectra were averaged to provide a blank. Blank corrected absorbance spectra were then corrected for offsets due to scattering and instrument drift by subtraction of the average absorbance between 700 and $800 \mathrm{~nm}$ (Stubbins et al., 2011). Data output from the spectrophotometer were in the form of dimensionless absorbance or optical density (OD) and were subsequently converted to the Napierian absorption coefficient, $a\left(\mathrm{~m}^{-1}\right.$; $\mathrm{Hu}$ et al., 2002). Spectral slope $\left(\mathrm{S}, \mathrm{nm}^{-1}\right)$ in the ranges 275 to $295 \mathrm{~nm}$ and 350 to $400 \mathrm{~nm}$, together with the ratio of these slopes (slope ratio) were calculated following Helms et al. (2008).

\subsection{Dissolved organic carbon}

The total amount of DOM in a sample was defined in terms of the major building block of dissolved organics, DOC. In order to analyse DOC, the rest of the sample was acidified to $\mathrm{pH} 2$ by addition of hydrochloric acid (p.a.) to the irradiation flasks. A subsample was then taken and analyzed for non-purgable organic carbon using a Shimadzu TOCVCPH analyzer fitted with a Shimadzu ASI-V autosampler following the methodology recommended by the manufacturer. Standards were prepared by the volumetric dilution of a stock solution containing $500 \mu \mathrm{m}-\mathrm{DOC}$ (potassium hydrogen phthalate, p.a.) to produce the following series of standards: $0,2,5,8,10,25,50,75,100 \mu \mathrm{m}$-DOC. In addition to standards, aliquots of deep seawater reference material, Batch 10, Lot\# 05-10, from the Consensus Reference Material Project (CRM) were analyzed to check the precision and accuracy of the DOC analyses. Analyses of the CRM deviated by less than $5 \%$ from the reported value for these standards (41 to $44 \mu \mathrm{m}$-DOC; http://yyy.rsmas.miami. edu/groups/biogeochem/Table1.htm). Standard and sample volumes analyzed were 20 to $40 \mathrm{~mL}$. Routine minimum detection limits in the investigators, laboratory using the above configuration are $2.8 \pm 0.3 \mu \mathrm{m}-\mathrm{C}$ and standard errors are typically $1.7 \pm 0.5 \%$ of the DOC concentration (Stubbins and Dittmar, 2012).

\subsection{Solid phase extraction}

The remaining volume (1507 to $1975 \mathrm{~mL}$ ) of acidified seawater was then solid phase extracted following the method of Dittmar et al. (2008). In brief, samples were loaded onto $1 \mathrm{~g}$ Varian Bond Elut PPL solid phase extraction columns at a flow rate of approximately $2 \mathrm{~mL}$ per minute. The columns were then rinsed with $20 \mathrm{~mL}$ of $\mathrm{pH} 2$ ultrapure water to wash off residual salts and dried with zero grade air (AirGas) before being eluted with $6 \mathrm{~mL}$ of HPLC grade methanol (Fisher). The DOC extraction efficiency was determined for each sample by evaporating an aliquot of the methanol extract to dryness, redissolving it into a known volume of ultrapure water and determining the DOC concentration in this solution. The DOC in the aliquot of dried methanol (mgC) was calculated as the concentration in the aqueous solution multiplied by the aqueous solution's volume. The total DOC yield (mg-C) in the $6 \mathrm{~mL}$ of methanol eluate was then calculated by multiplying the dried aliquot's DOC yield by $6 \mathrm{~mL}$ and dividing by the volume of methanol aliquot that was dried. The percentage yield was then determined by dividing the total DOC yield by the amount of DOC originally passed through the columns (i.e. the concentration of DOC in the irradiated NADW aliquots multiplied by the volume of each aliquot loaded onto the PPL columns).

\subsection{Dissolved black carbon quantification}

Dissolved black carbon was determined at the molecular level via a modified version of the benzenepolycarboxylic acid (BPCA) method after Dittmar (2008). In brief, 140 to $600 \mu \mathrm{L}$ of the PPL methanol extracts, corresponding to 
$\sim 2 \mu \mathrm{mol}$ DOC, were transferred into pre-combusted $\left(400^{\circ} \mathrm{C}\right.$, 4h) $1 \mathrm{~mL}$ glass ampoules, dried over night at $50{ }^{\circ} \mathrm{C}$ in an oven, and then redissolved in $500 \mu \mathrm{L}$ of nitric acid $(65 \%$, p.a.). The ampoules were then sealed and heated to $170^{\circ} \mathrm{C}$ in a stainless steel pressure bomb inside a furnace for $9 \mathrm{~h}$. After the ampoules had cooled, aliquots of $450 \mu \mathrm{L}$ were transferred into $1 \mathrm{~mL}$ maximum recovery vials (Waters). The nitric acid was evaporated in a centrifugal evaporator (RVC 2-18, Christ, Germany) and the samples were redissolved in $100 \mu \mathrm{L}$ of phosphate buffer solution $\left(\mathrm{Na}_{2} \mathrm{HPO}_{4}\right.$ and $\mathrm{NaH}_{2} \mathrm{PO}_{4}$ each $5 \mathrm{mM}$ in ultrapure water, buffered $\mathrm{pH}$ 7.2). BPCAs were quantified on a Waters ACQUITY UPLC (Ultra Performance Liquid Chromatography) system composed of a binary solvent manager, a sample manager, a column manager and a photodiode array light absorbance detector (PDA e $\lambda)$. BPCAs were separated on a Waters ACQUITY UPLC BEH C18 Column $(2.1 \times 150 \mathrm{~mm}, 1.7 \mu \mathrm{m})$ with an aqueous phase / methanol gradient modified after Dittmar (2008). The aqueous phase consisted of a tetrabutylammonium bromide solution (4 mM, ACS quality) in phosphate buffer $\left(\mathrm{Na}_{2} \mathrm{HPO}_{4}\right.$ and $\mathrm{NaH}_{2} \mathrm{PO}_{4}$ each $5 \mathrm{mM}$ in ultrapure water, $\mathrm{pH}$ 7.2). The injection volume was $10 \mu \mathrm{L}$. BPCAs were identified according to retention time and absorbance spectra (220 to $380 \mathrm{~nm})$. Quantification was performed using the adsorption signal at $240 \mathrm{~nm}$ and external calibration. B3CAs and to some degree B4CAs are decomposed during the nitric acid oxidation procedure which negatively impacts the reproducibility and precision of the method (Dittmar, 2008). Furthermore, 1,2,4,5B4CA is the only B4CA that is commercially available as a standard. Therefore, only the three robustly quantifiable BPCAs: 1,2,4,5-B4CA, B5CA and B6CA are reported. An extensive BPCA data set collected for the Southern Ocean (Dittmar and Paeng, 2009), the Gulf of Mexico (Dittmar et al., 2012) and other regions (unpublished) was used to develop a power-function relationship $\left(R^{2}=0.998 ; n=352\right)$ to predict the concentration of DBC from the sum of the quantitatively dominant and robustly quantified B5CA and B6CA. This extrapolation reduced the analytical error range of replicate analysis for the calculation of total DBC within the model dataset to below $2 \%$ and provided a method to compare the data reported here with the total DBC concentrations reported elsewhere (Dittmar, 2008; Dittmar and Paeng, 2009). The concentrations of the individual BPCAs quantified are reported in Table 1 to enable comparison to other data on a BPCA by BPCA basis. The individual BPCA and total DBC concentrations reported here should be regarded as conservative estimates as either their extraction from the water column using PPL or their recovery during oxidation may not have been $100 \%$ efficient.

\section{Results and discussion}

\subsection{Dissolved organic carbon and coloured dissolved organic matter photo-degradation}

Concentrations of DOC decreased $76 \pm 8 \%$ during the irradiation of NADW, falling from an initial $50.8 \pm 0.4 \mu \mathrm{m}$ to $12.3 \pm 4.2 \mu \mathrm{m}$ over 28 days (Table 1 ). Previous longterm irradiation studies report that photo-labile DOC constitutes between zero and $90 \%$ of bulk DOC, with the highest percentage DOC photo-mineralisation reported for wetland plant leachates (Vähätalo and Wetzel, 2004). Two terrestrially dominated, high CDOM natural waters contained $\sim 45 \%$ photo-labile DOC (Obernosterer and Benner, 2004; Spencer et al., 2009), whereas photo-labile DOC made up less than $10 \%$ of total DOC in a phytoplankton dominated lake and the waters of a phytoplankton culture (Obernosterer and Benner, 2004).

The previous irradiations noted above were conducted under various light sources, in irradiation vessels of varying pathlength and include samples with varying absorption coefficients. As such, the quantity and quality of light received by CDOM chromophores varied between those studies and the work presented here. Nevertheless, it is apparent that in terms of its photo-lability, NADW DOC has more in common with the terrestrially influenced samples than those freshly derived from phytoplankton. Lignin in solid phase extracts and the $\delta^{13} \mathrm{C}$ of high molecular weight DOM, both signatures of DOM source, indicate that terrestrial DOM is exported to NADW from the Arctic Ocean (Hernes and Benner, 2006). However, Hernes and Benner (2006) also suggest that such terrestrial inputs constitute only $1.6 \%$ of deep water DOC at BATS. It is therefore unlikely that the elevated photo-lability of NADW DOC stems principally from terrestrial inputs. Deep water DOM in the North Atlantic, as in other basins, has an apparent age of approximately 4000 years before present based upon $\Delta^{14}$ C-DOC (Bauer, 2002). Four thousand years is longer than the turnover time of the ocean and suggests a pool of highly recalcitrant DOM persists in the dark of the deep ocean. Furthermore, microbe and animal heterotrophs produce CDOM when utilizing biolabile forms of organic matter (e.g. Ortega-Retuerta et al., 2009) and it has been suggested that the refractory DOM is not just conserved in the deep ocean, but that the microbes of the deep ocean rework DOM and sinking particles producing more recalcitrant (Jiao et al., 2010), more coloured DOM (Yamashita and Tanoue, 2008; Nelson et al., 2010), much in the same way as microbes produce coloured humic materials in soils. Therefore the high photo-lability of NADW DOC may result from inputs of terrestrial DOM and/or the reworking of autochthonous marine DOM and sinking particles into more coloured, photo-labile forms.

CDOM light absorption at $300 \mathrm{~nm}$ decreased $95 \pm 5 \%$ from $0.35 \pm 0.02 \mathrm{~m}^{-1}$ to $0.02 \pm 0.02 \mathrm{~m}^{-1}$ during the irradiation (Table 1). That close to $100 \%$ of CDOM absorbance 
Table 1. Summary of results of North Atlantic Deep Water photodegradation over 28 days. Parameters included: dissolved organic carbon (DOC), coloured dissolved organic matter Naperian absorption coefficient at $300 \mathrm{~nm}\left(\mathrm{CDOM} \alpha_{300}\right)$, spectral slope in the range $275-295 \mathrm{~nm}$ $\left(S_{275-295}\right)$, the slope ratio $\left(S_{275-295}: S_{350-400}\right)$, percentage of total DOC extractable using PPL, the concentration of dissolved black carbon (DBC), DBC as a percentage of total DOC, and the concentrations and ratios of the individual DBC derived benzenepolycarboxylic acids.

\begin{tabular}{|c|c|c|c|c|c|c|c|c|c|c|c|c|c|}
\hline $\begin{array}{l}\text { Time } \\
\text { (days) }\end{array}$ & $\begin{array}{l}\text { DOC } \\
(\mu \mathrm{M})\end{array}$ & $\begin{array}{l}\mathrm{CDOM} \alpha_{300} \\
\left(\mathrm{~m}^{-1}\right)\end{array}$ & $\begin{array}{l}S_{275-295} \\
\left(\mathrm{~nm}^{-1}\right)\end{array}$ & $\begin{array}{l}\text { Slope* } \\
\text { ratio }\end{array}$ & $\begin{array}{l}\% \text { DOC } \\
\text { extracted }\end{array}$ & $\begin{array}{l}\mathrm{DBC} \\
(\mathrm{nM})\end{array}$ & $\begin{array}{l}\% \\
\mathrm{DBC}\end{array}$ & $\begin{array}{l}\mathrm{B} 4^{\#} \\
(\mathrm{nM})\end{array}$ & $\begin{array}{l}\text { B5 } \\
(\mathrm{nM})\end{array}$ & $\begin{array}{l}\text { B6 } \\
(\mathrm{nM})\end{array}$ & $\begin{array}{l}\text { B5/ } \\
\text { B4 }\end{array}$ & $\begin{array}{l}\text { B6/ } \\
\text { B4 }\end{array}$ & $\begin{array}{l}\text { B6/ } \\
\text { B5 }\end{array}$ \\
\hline 0 & $50.8 \pm 0.4$ & $0.35 \pm 0.02$ & -0.021 & 1.6 & $74 \pm 2$ & $1044 \pm 164$ & 2.1 & $3.2 \pm 0.4$ & $16.3 \pm 2.6$ & $5.2 \pm 0.9$ & 5.1 & 1.6 & 0.32 \\
\hline 2 & $49.9 \pm 1.8$ & $0.28 \pm 0.04$ & -0.039 & 2.6 & $70 \pm 4$ & $872 \pm 38$ & 1.7 & $2.9 \pm 0.2$ & $13.9 \pm 0.7$ & $3.9 \pm 0.1$ & 4.8 & 1.4 & 0.28 \\
\hline 6 & $47.4 \pm 2.6$ & $0.22 \pm 0.03$ & -0.046 & 4.0 & $70 \pm 5$ & $741 \pm 15$ & 1.6 & $2.7 \pm 0.1$ & $11.8 \pm 0.2$ & $3.2 \pm 0.1$ & 4.4 & 1.2 & 0.27 \\
\hline 28 & $12.3 \pm 4.2$ & $0.02 \pm 0.02$ & -0.089 & - & $67 \pm 5$ & $55 \pm 15$ & 0.2 & $0.2 \pm 0.1$ & $0.9 \pm 0.3$ & $0.2 \pm 0.0$ & 3.9 & 0.9 & 0.23 \\
\hline
\end{tabular}

*No slope ratio is presented for 28 days as the slope from 350 to $400 \mathrm{~nm}$ was not measurable using a $10 \mathrm{~cm}$ path length cuvette.

\# B4 in this study refers solely to 1,2,4,5-Benzenetetracarboxylic acid.

was photo-labile is consistent with results from long-term irradiation studies of freshwaters (Vähätalo and Wetzel, 2004; Spencer et al., 2009). In further agreement with previous work studying the photo-degradation of DOM from freshwaters (Obernosterer and Benner, 2004; Spencer et al., 2009), estuaries (Moran et al., 2000), plant leachates (Vähätalo and Wetzel, 2004) and a phytoplankton culture (Obernosterer and Benner, 2004), CDOM was found to bleach more efficiently than bulk DOC (Table 1). The spectral slope between 275 and $295 \mathrm{~nm}\left(\mathrm{~S}_{275-295}\right)$ became steeper and the slope ratio ( $S_{275-295}: S_{350-400}$; (Helms et al., 2008) became greater as the irradiation proceeded (Table 1). Such trends in these two parameters are indicative of a decrease in molecular weight and are generally observed during CDOM photo-bleaching (Helms et al., 2008).

\subsection{PPL solid phase recovery of dissolved organic carbon}

The percentage of DOC that was recovered using PPL solid phase extraction decreased slightly from $74 \pm 2 \%$ for the initial sample to $67 \pm 5 \%$ after 28 days of irradiation (Table 1) suggesting the preferential photo-degradation of stickier, hydrophobic molecules. The modest decrease in extraction efficiencies $(7 \pm 7 \%)$ occurred alongside major gross removal of DOC $(>75 \%)$ and shifts in the quality of DOM as indicated by the shifts in carbon normalised light absorption and spectral slope parameters (Table 1).

\subsection{Quantitative dissolved black carbon photo-degradation}

Dissolved black carbon occurred at a concentration of $1044 \pm 164$ nM-C in NADW prior to irradiation. This is slightly higher than in the deep waters of the Southern Ocean (Dittmar and Paeng, 2009). During the irradiation, each of the analysed BPCAs decreased significantly and continuously, resulting in a decrease in total DBC from $1044 \pm 164$ nM-C to $55 \pm 15$ nM-C (Fig. 1a; Table 1). This equates to a $95 \%$ decrease over the 28 day irradiation and corroborates earlier work in which all DBC compounds identified in Fourier transform ion cyclotron (FT-ICR) mass spectra of Congo River water were absent after 57 days of irradiation under the same solar simulator used here (Stubbins et al., 2010) and other FT-ICR MS studies which noted a reduction in condensed compounds in DOM extracts following irradiation (Kujawinski et al., 2004; Gonsior et al., 2009). The magnitude of these losses demonstrates that photo-degradation could be an important process for DBC removal from natural waters, and may explain the low concentrations of DBC observed in Southern Ocean surface waters (Dittmar and Paeng, 2009).

The percentage of total DOC constituted by DBC decreased from $2.1 \%$ at the start to $0.2 \%$ at the end of the irradiation (Fig. 1b; Table 1). The decrease in the carbonnormalised DBC shows that DBC, like CDOM and aromatic compounds such as lignin (Opsahl and Benner, 1998; Vähätalo et al., 1999; Spencer et al., 2009), is preferentially photo-degraded relative to bulk DOC. DBC concentrations fell hand-in-hand with CDOM $a_{300}$ (Fig. 2) indicating tight coupling between the photo-degradation of condensed aromatics (DBC) and the loss of bulk aromatic carbon as typified by CDOM. Previous work with ${ }^{14} \mathrm{C}$-labelled compounds demonstrated that the core aromatic structures of synthetic lignin are photo-mineralised to carbon dioxide (Vähätalo et al., 1999). Though the current study does not resolve the mechanism of DBC photo-degradation, the concomitant loss of $\sim 76 \%$ of DOC during the irradiation suggests that much of the DBC is also mineralised to carbon dioxide and carbon monoxide, the main inorganic photo-products of DOC photodegradation (Miller and Zepp, 1995; Mopper and Kieber, 2002).

\subsection{Qualitative dissolved black carbon photo-degradation}

The molecular DBC method as applied here quantifies three broad classes of DBC oxidation products, each with a different number of carboxylic groups (Dittmar, 2008). These are the: benzeneTETRAcarboxylic acids (B4; only the 1,2,4,5-B4CA isomer was quantified here); 

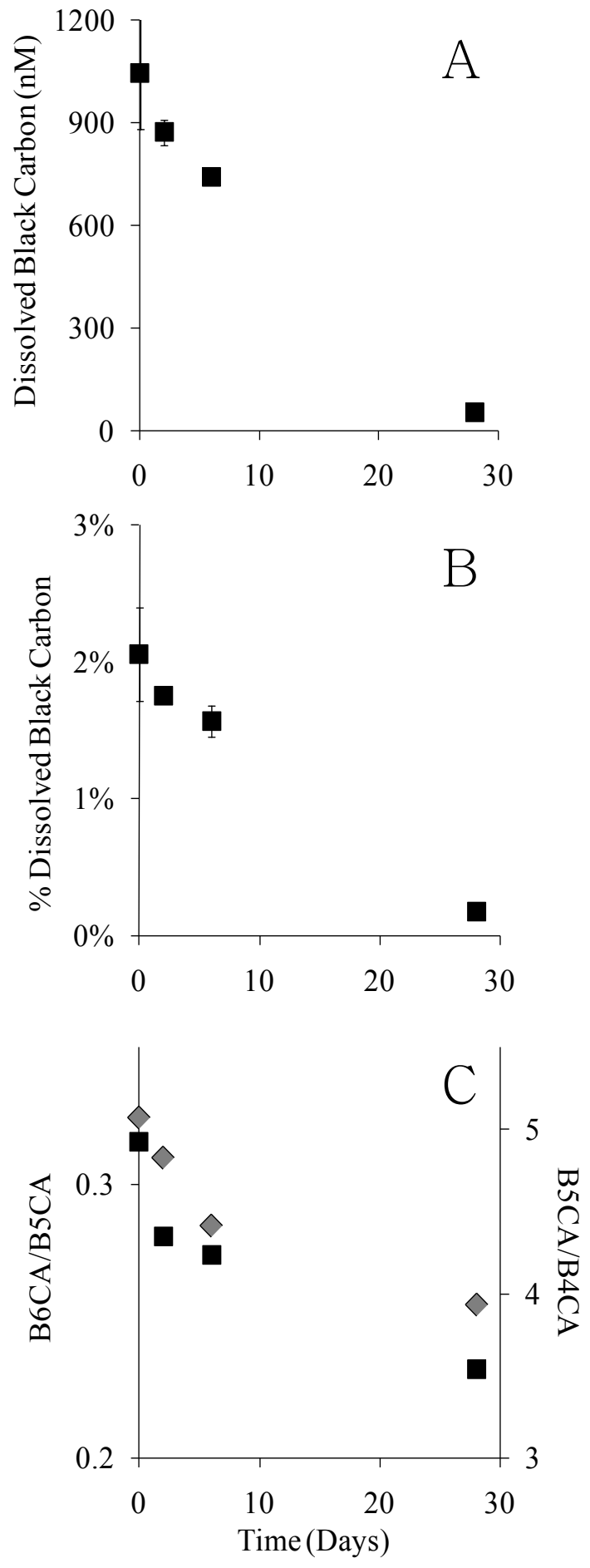

Fig. 1. Photodegradation of dissolved black carbon (DBC) in North Atlantic Deep Water over the course of a 28 day irradiation. Panel A: DBC concentration. Panel B: DBC as a percentage of total dissolved organic carbon. Panel C: ratios of DBC derived benzenecarboxylic acids. Ratios decrease as DBC becomes less condensed. Black squares are B6CA/B5CA. Grey diamonds are B5CA/B4CA.
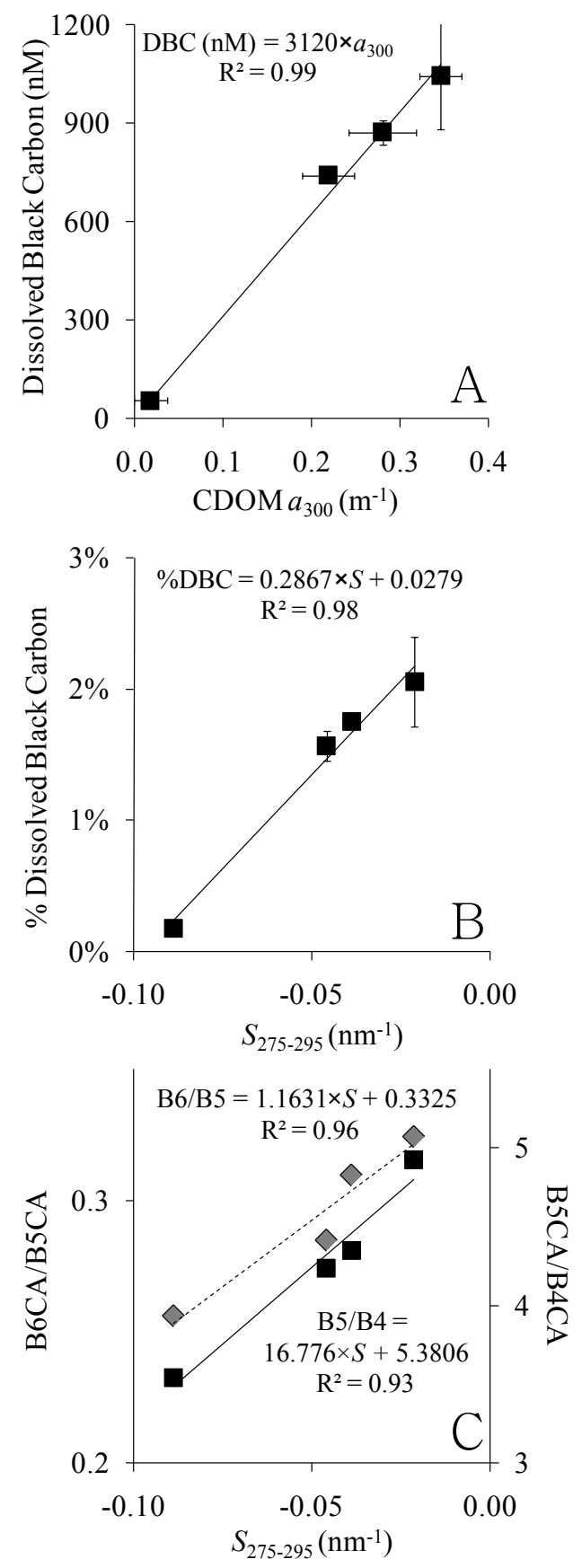

Fig. 2. Correlations between the optical properties of coloured dissolved organic matter (CDOM) and dissolved black carbon (DBC) quantity and quality over the course of a 28 day irradiation. Panel A: DBC concentration versus the CDOM Naperian absorption coefficient at $300 \mathrm{~nm}\left(\mathrm{CDOM} a_{300}\right)$. Panel B: DBC as a percentage of total dissolved organic carbon versus the CDOM spectral slope between 275 and $295 \mathrm{~nm}\left(S_{275-295}\right)$. Panel C: ratios of DBC derived benzenecarboxylic acids versus $S_{275-295}$. Black squares and solid regression line are for B6CA/B5CA. Grey diamonds and broken regression line are for $\mathrm{B} 5 \mathrm{CA} / \mathrm{B} 4 \mathrm{CA}$. 
benzenePENTAcarboxylic acid (B5); and, benzeneHEXAcarboxylic acid (B6). Each of these BPCAs provides structural information about DBC. B6 is indicative of highly condensed aromatics, whereas the benzene products with lower numbers of carboxylic substitutes are indicative of molecules with smaller numbers of condensed rings at their core (Schneider et al., 2010). North Atlantic Deep Water DBC had a B6/B5 of 0.32 (Table 1; Fig. 1c) consistent with the seawater samples analyzed by Dittmar (2008) and the relatively small size and low levels of condensation of polyaromatics identified in the oceans by FT-ICR MS (Dittmar and Koch, 2006).

In addition to reducing the amount of $\mathrm{DBC}$, photodegradation of DOM also altered the ratio of the different classes of BPCA discussed above. Figure 1c presents the trends in $\mathrm{B} 6 / \mathrm{B} 5$ and $\mathrm{B} 5 / \mathrm{B} 4$, which decreased as DBC became less condensed during the photo-degradation (note: $\mathrm{B} 5 / \mathrm{B} 4$ is calculated as the ratio of B5CA to $1,2,4,5-\mathrm{B} 4 \mathrm{CA}$ and is therefore an overestimate of the ratio of B5CA to all possible B4CA isomers). This shift towards less condensed DBC components during irradiation is seen for all the ratios of BPCAs (Table 1). The steepening of spectral slope $\left(S_{275-295}\right)$ during the irradiation was correlated with \% DBC and with the values for B6/B5 and B5/B4 (Fig. 2b and c; Table 1) verifying that $S_{275-295}$ is a valuable proxy for the aromatic quality of DOM and that $S_{275-295}$ may also provide a proxy for the tracking of DBC quality (B6:B5:B4) in natural waters.

The changes in DBC as a percentage of bulk DOC and the ratios of the various BPCAs to one another (Table 1) indicate a continuum of photo-labile DOM. In this continuum, lability follows the trend $\mathrm{B} 6>\mathrm{B} 5>\mathrm{B} 4>$ bulk DOC, i.e. the more condensed a compound, the more photo-labile it will be. A result in agreement with Fourier transform ion cyclotron mass spectrometry data from an irradiation study of Congo River water (Stubbins et al., 2010). Presumably the less condensed aromatics that yield B3CA oxidation products and were not quantified here would be less photo-reactive than their more condensed analogues. Photo-degradation may be responsible for the shift from highly condensed aromatics seen in terrestrial waters to less condensed DBC structures identified in the open ocean (compare values for different environments in Dittmar and Paeng, 2009; Dittmar, 2008; Ziolkowski and Druffel, 2010). Ratios between BPCAs will likely provide useful proxies for the photo-degradation state of DBC, much the same as acid:aldehyde ratios are indicative of lignin diagenesis (Hedges et al., 1988; Opsahl and Benner, 1995; Spencer et al., 2009). By extension, DBC:DOC and BPCA ratios should also offer insight into the irradiation history of the bulk DOM pool within a water body. Critical to the use of these ratios as indicators of photo-degradation history will be an understanding of other factors that may also alter BPCA ratios. Factors of potential relevance include, but are not limited to, differences in source material (Guggenberger et al., 2008; Haumaier, 2010), aging in soil (Abiven et al., 2011) or the water column, and sorption, the latter having a significant influence upon the ratios of various lignin-derived phenols (Hernes et al., 2007).

\subsection{The oceanic photo-chemical sink of dissolved black carbon}

Although further work is required to determine the photolability of DBC in other waters and to conduct more controlled apparent quantum yield experiments designed for the calculation of environmentally relevant DBC photodegradation rates, the data presented here can be used to generate an initial, though poorly constrained estimate for the photo-chemical turnover of DBC in the global ocean. In the current irradiations, the photo-degradation of DBC and CDOM light absorption were well correlated (Fig. 2a), unfortunately there is no estimate of the global oceanic photo-chemical CDOM sink for use in scaling DBC photodegradation to the global ocean. However, DBC to DOC photo-degradation ratios can be used and scaled to estimates of global DOC photo-mineralisation. Dissolved black carbon constituted $18 \%$ of total DOC photo-mineralisation after two days. After 28 days DBC contributed only $3 \%$ to the total DOC loss. The photo-degradation state of DOM in natural surface waters is hard to predict making it unclear which of these ratios more closely represents the ratio of DBC:DOC photo-degradation in the open ocean. Therefore, each of these ratios was scaled to total oceanic DOC photomineralisation, rates of which, not including the photoproduction of bio-labile DOC, have been estimated to be between 705 and $2680 \mathrm{Tg}^{-} \mathrm{C} \mathrm{yr}^{-1}$ (Mopper and Kieber, 2001; Stubbins et al., 2006). Scaling DBC photo-degradation to upper and lower limits for both DBC:DOC photo-degradation ratios and estimates of DOC loss resulted in global DBC photo-mineralisation rates of between 20 to $490 \mathrm{Tg}^{-C} \mathrm{yr}^{-1}$. Assuming that DBC constitutes about $2 \%$ of the $700 \mathrm{Pg}-\mathrm{C}$ of DOC in the global ocean (Dittmar and Paeng, 2009), the 14 Pg-C standing stock of oceanic DBC could be completely photo-degraded within 28 to 773 years. This initial estimate is considerably shorter than the apparent age of DBC in the open ocean (Ziolokowski and Druffel, 2010), suggesting that photo-chemistry is the dominant sink for marine DBC. Therefore, the apparent persistence of DBC in the oceans for millennia is facilitated not by the inherent inertness of DBC molecules, but by the slow pace of ocean turnover which controls the supply of DBC to photic surface waters.

\section{Conclusions}

In surface and deep ocean waters the high molecular weight fraction of $\mathrm{DBC}$ has the greatest apparent age of any widespread, dissolved organic compound (radiocarbon age $>15000$ years before present; Ziolkowski and Druffel, 2010) and in the deep ocean DBC concentrations show limited 
variability (Dittmar and Paeng, 2009). Such results indicate that oceanic DBC is highly refractory. Although DBC in surface waters is apparently old, its concentrations vary, with higher concentrations associated with coastal inputs and lowest concentrations found in the open ocean (Dittmar and Paeng, 2009). This spatial trend is analogous to that for CDOM, which is elevated in coastal waters and depleted in the open ocean gyres, with the major global trends in surface waters driven by coastal inputs and removal through photodegradation (Blough and Del Vecchio, 2002; Coble et al., 2002; Nelson and Siegel, 2002; Nelson et al., 2007; Del Vecchio et al., 2009). Though data is much scarcer for DBC, it appears that these same processes may also control DBC distribution in surface waters. The data presented here certainly indicate DBC to be highly photo-labile with $\sim 95 \%$ of DBC in the initial sample being lost within 28 days of irradiation (Fig. 1a; Table 1) and an estimate of the rate of DBC photodegradation in the global ocean indicates that the entire stock of oceanic DBC could be photo-degraded in approximately 30 to 800 years.

Total DBC was correlated with CDOM light absorption throughout the experiment (Fig. 2a). Similarly, the \% contribution of DBC to total DOC and the ratios of BPCAs to one another correlated with the CDOM spectral slope (Fig. 2a and $b$ ). These correlations suggest that the optical properties of the total oceanic CDOM pool are closely related to the amount and quality of DBC present. These correlations also suggest that CDOM optical properties may prove to be useful proxies for the concentration and the quality of DBC present in natural waters. The great power of these proxies is that they would allow DBC concentrations to be estimated from the thousands of existing CDOM data points in publications (e.g. Kitidis et al., 2006; Siegel and Michaels, 1996; Nelson et al., 1998; Rochelle-Newall et al., 1999; Siegel et al., 2005; Nelson and Siegel, 2002; Yamashita and Tanoue, 2004) and in open databases (e.g. www.icess.ucsb.edu/GlobalCDOM; www.nodc.noaa.gov; http://bcodmo.org/; www.bodc.ac.uk and www.pangaea.de/). Optical proxies would also enable the remote sensing of surface DBC based upon robust estimates of the CDOM absorbance in surface waters (e.g. Siegel et al., 2002). Further work is required to determine relationships between DBC and CDOM optical properties in natural waters.

New analytical techniques have delivered an understanding that DOM is an assortment of molecules and this understanding has led to the development or borrowing of new tools to look ever closer at dissolved organic molecules. On examination the chemistries and reactivities of the molecules differ widely from one another, such that two molecules from the same locations (soil, river, ocean) can have wildly different fates in the environment. It therefore makes sense to subdivide the DOM pool where possible, building up global budgets for quantifiable components of the DOM pool. In the case of DBC, a logical approach would be to build a budget for each BPCA, to relate this to total DBC, and finally, where relevant and with careful assumptions, to relate this to the cycling of more inclusive components of the DOM pool, such as photo-labile or bio-refractory DOM, for which DBC seems to offer a promising tracer.

Acknowledgements. We would like to thank the crew of the RV Atlantic Explorer and the Bermuda Institute of Ocean Sciences for assistance with sample collection, and Ina Ulber for technical support. This work was supported by the National Science Foundation (OCE-0327446 and OCE-0728634) and a Fellowship from the Hanse Institute for Advanced Studies (HWK, Delmenhorst, Germany) granted to Stubbins. Any opinions, findings, conclusions or recommendations expressed in this paper are those of the authors and do not necessarily reflect the views of the funding bodies.

Edited by: G. Herndl

\section{References}

Abiven, S., Heim, A., and Schmidt, M. W. I.: Lignin content and chemical characteristics in maize and wheat vary between plant organs and growth stages: consequences for assessing lignin dynamics in soil, Plant Soil, 343, 369-378, 2011.

Bauer, J. E.: Carbon isotopic composition of DOM, in: Biogeochemistry of Marine Dissolved Organic Matter, Academic Press, Boston, USA, 405-453, 2002.

Blough, N. V. and Del Vecchio. R.: Chromophoric DOM in the coastal environment, in: Biogeochemistry of Marine Dissolved Organic Matter, Academic Press, Boston, USA, 509-546, 2002.

Coble, P., Hu, C., Gould, Jr., R. W., Chang, G., and Wood, A. M.: Colored Dissolved Organic Matter in the Coastal Ocean: An Optical Tool for Coastal Zone Environmental Assessment and Management, Oceanogr., 17, 50-59, 2004.

Del Vecchio, R., Subramaniam, A., Schollaert Uz, S., BallabreraPoy, J., Brown, C. W., and Blough, N. V.: Decadal time-series of SeaWiFS retrieved CDOM absorption and estimated CO2 photoproduction on the continental shelf of the eastern United States, Geophys. Res. Lett., 36, L02602, doi:10.1029/2008GL036169, 2009.

Dittmar, T.: The molecular level determination of black carbon in marine dissolved organic matter, Org. Geochem., 39, 396-407, 2008.

Dittmar, T. and Koch, B. P.: Thermogenic organic matter dissolved in the abyssal ocean, Mar. Chem., 102, 208-217, 2006.

Dittmar, T. and Paeng, J.: A heat-induced molecular signature in marine dissolved organic matter, Nat. Geosci., 2, 175-179, 2009.

Dittmar, T., Koch, B., Hertkorn, N., and Kattner, G.: A simple and efficient method for the solid-phase extraction of dissolved organic matter (SPE-DOM) from seawater, Limnol. Oceanogr. Methods, 6, 230-235, 2008.

Dittmar, T., Paeng, J., Gihring, T. M., Suryaputra, I. G. N. A., and Huettel, M.: Discharge of dissolved black carbon from a fireaffected intertidal system, Limnol. Oceanogr., in press, 2012.

Druffel, E. R. M.: Comments on the importance of black carbon in the global carbon cycle, Mar. Chem., 92, 197-200, 2004.

Gonsior, M., Peake, B. M., Cooper, W. T., Podgorski, D., D'Andrilli, J., and Cooper, W. J.: Photochemically induced 
changes in dissolved organic matter identified by ultrahigh resolution Fourier transform ion cyclotron resonance mass spectrometry, Environ. Sci. Technol., 43, 698-703, 2009.

Guggenberger, G., Rodionov, A., Shibistova, O., Grabe, M., Kasansky, O. A., Fuchs, H., Mikheyeva, N., Zrazhevskaya, G., and Flessa, H.: Storage and mobility of black carbon in permafrost soils of the forest tundra ecotone in Northern Siberia, Global Change Biol., 14, 1367-1381, 2008.

Hansell, D. A.: DOC in the Global Ocean Carbon Cycle, in: Biogeochemistry of Marine Dissolved Organic Matter, Academic Press, Boston, USA, 685-715, 2002.

Haumaier, L.: Benzene polycarboxylic acids-A ubiquitous class of compounds in soils, J. Plant Nutrit. Soil Sci., 173, 727-736, 2010.

Hedges, J. I.: Why dissolved organics matter, in: Biogeochemistry of Marine Dissolved Organic Matter, Academic Press, Boston, USA, 1-33, 2002.

Hedges, J. I., Blanchette, R. A., Weliky, K., and Devol, A. H.: Effects of fungal degradation on the $\mathrm{CuO}$ oxidation products of lignin: a controlled laboratory study, Geochim. Cosmochim. Acta, 52, 2717-2726, 1988.

Helms, J. R., Stubbins, A., Ritchie, J. D., Minor, E. C., Kieber, D. J., and Mopper, K.: Absorption spectral slopes and slope ratios as indicators of molecular weight, source, and photobleaching of chromophoric dissolved organic matter, Limnol. Oceanogr., 53, 955-969, 2008.

Hernes, P. J. and Benner, R.: Terrigenous organic matter sources and reactivity in the North Atlantic Ocean and a comparison to the Arctic and Pacific Oceans, Mar. Chem., 100, 66-79, 2006.

Hernes, P. J., Robinson, A. C., and Aufdenkampe, A. K.: Fractionation of lignin during leaching and sorption and implications for organic matter "freshness", Geophys. Res. Lett., 34, L17401, doi:10.1029/2007GL031017, 2007.

Hu, C. M., Muller-Karger, F. E., and Zepp, R. G.: Absorbance, absorption coefficient, and apparent quantum yield: A comment on common ambiguity in the use of these optical concepts, Limnol. Oceanogr., 47, 1261-1267, 2002.

Jiao, N., Herndl, G. J., Hansell, D. A., Benner, R., Kattner, G., Wilhelm, S. W., Kirchman, D. L., Weinbauer, M. G., Luo, T., Chen, F., and Azam, F.: Microbial production of recalcitrant dissolved organic matter: long-term carbon storage in the global ocean, Nature Rev. Micro., 8, 593-599, 2010.

Jurado, E., Dachs, J., Duarte, C. M., and Simó, R.: Atmospheric deposition of organic and black carbon to the global oceans, Atmos. Env., 42, 7931-7939, 2008.

Kaiser, K. and Benner, R.: Biochemical composition and size distribution of organicmatter at the Pacific and Atlantic times-series stations. Mar. Chem., 113, 63-77, doi:10.1016/j.marchem.2008.12.004, 2009.

Keiluweit, M., Nico, P. S., Johnson, M. G., and Kleber, M.: Dynamic Molecular Structure of Plant Biomass-Derived Black Carbon (Biochar), Environ. Sci. Technol., 44, 1247-1253, 2010.

Kim, S., Kaplan, L. A., Benner, R., and Hatcher, P. G.: Hydrogendeficient molecules in natural riverine water samples-evidence for the existence of black carbon in DOM, Mar. Chem., 92, 225234, 2004.

Kujawinski, E. B., Del Vecchio, R., Blough, N. V., Klein, G. C., and Marshall, A. G.: Probing molecular-level transformations of dissolved organic matter: insights on photochemical degradation and protozoan modification of DOM from electrospray ionization Fourier transform ion cyclotron resonance mass spectrometry, Mar. Chem., 92, 23-37, 2004.

Kuo, L.-J., Herbert, B. E., and Louchouarn, P.: Can levoglucosan be used to characterize and quantify char/charcoal black carbon in environmental media? Org. Geochem., 39, 1466-1478, 2008.

Mannino, A. and Harvey, H. R.: Black carbon in estuarine and coastal ocean dissolved organic matter, Limnol. Oceanogr., 49, 735-740, 2004.

Miller, W. L. and Zepp, R. G.: Photochemical production of dissolved inorganic carbon from terrestrial organic-matter: Significance to the oceanic organic-carbon cycle, Geophys. Res. Lett., 22, 417-420, 1995.

Mopper, K. and Kieber, D. J.: Impact of DOM Photochemistry on the Biogeochemical Cycling of Carbon, Nitrogen, Sulfur and Phosphorus in the Sea, in: Biogeochemistry of Marine Dissolved Organic Matter, edited by: Carlson, C. and Hansell, D., Academic Press, 456-503, 2002.

Moran, M. A., Sheldon, W. M., and Zepp, R. G.: Carbon loss and optical property changes during long-term photochemical and biological degradation of estuarine dissolved organic matter, Limnol. Oceanogr., 45, 1254-1264, 2000.

Nelson, N. B. and Siegel, D. A.: Chromophoric DOM in the Open Ocean, in: Biogeochemistry of Marine Dissolved Organic Matter, Academic Press, Boston, USA, 547-578, 2002.

Nelson, N. B., Siegel, D. A., Carlson, C. A., Swan, C., Smethie, Jr., W. M., and Khatiwala, S.: Hydrography of chromophoric dissolved organic matter in the North Atlantic, Deep-Sea Res. I, 54, 710-731, 2007.

Nelson, N. B., Siegel, D. A., Carlson, C. A., and Swan, C. M.: Tracing global biogeochemical cycles and meridional overturning circulation using chromophoric dissolved organic matter, Geophys. Res. Lett., 37, L03610, doi:10.1029/2009GL042325, 2010.

Obernosterer, I. and Benner, R.: Competition between biological and photochemical processes in the mineralization of dissolved organic carbon, Limnol. Oceanogr., 49, 117-124, 2004.

Opsahl, S. and Benner, R.: Early diagenesis of vascular plant tissues, lignin and cutin decomposition and biogeochemical implications, Geochim. Cosmochim Acta., 59, 4889-4904, 1995.

Opsahl, S. and Benner, R.: Distribution and cycling of terrigenous dissolved organic matter in the ocean, Nature, 386, 480-482, 1997.

Opsahl, S. and Benner, R.: Photochemical reactivity of dissolved lignin in river and ocean waters, Limnol. Oceanogr., 43, 12971304, 1998.

Ortega-Retuerta, E., Frazer, T. K., Duarte, C. M., Ruiz-Halpern, S., Tovar-Sánchez, A., Arrieta, J. M., and Reche, I.: Biogeneration of chromophoric dissolved organic matter by bacteria and krill in the Southern Ocean, Limnol. Oceanogr., 54, 1941-1950, 2009.

Preston, C. M. and Schmidt, M. W. I.: Black(pyrogenic) carbon: a synthesis of current knowledge and uncertainties, Biogeoscienes, 3, 397-420, 2006.

Schneider, M. P. W., Hilf, M., Vogt, U. F., and Schmidt, M. W. I.: The benzene polycarboxylic acid (BPCA) pattern of wood pyrolyzed between $200^{\circ} \mathrm{C}$ and $1000^{\circ} \mathrm{C}$, Org. Geochem., 41, 10821088, 2010.

Siegel, D. A., Maritorena, S., Nelson, N. B., Hansell, D. A., and Lorenzi-Kayser, M.: Global distribution and dynamics of colored dissolved and detrital organic materials, J. Geophys. Res., 107, 
3228, doi:10.1029/2001JC000965, 2002.

Spencer, R. G. M., Stubbins, A., Hernes, P. J., Baker, A., Mopper, K., Aufdenkampe, A. K., Dyda, R. Y., Mwamba, V. L., Mangangu, A. M., Wabakanghanzi, J. N., and Six, J.: Photochemical degradation of dissolved organic matter and dissolved lignin phenols from the Congo River, J. Geophys. Res., 114, G03010, doi:10.1029/ 2009JG000968, 2009.

Stubbins, A. and Dittmar, T.: Low volume quantification of dissolved organic carbon and dissolved nitrogen, Limonol. Oceanogr. Methods, accepted, 2012.

Stubbins, A., Hubbard, V., Uher, G., Aiken, G., Law, C. S., UpstillGoddard, R. C., and Mopper, K.: Relating carbon monoxide photoproduction to dissolved organic matter functionality, Environ. Sci. Technol., 42, 3271-3276, 2008.

Stubbins, A., Spencer, R. G. M., Chen, H., Hatcher, P. G., Mopper, K., Hernes, P. J., Mwamba, V. L., Mangangu, A. M., Wabakanghanzi, J. N., and Six, J.: Illuminated darkness: molecular signatures of Congo River dissolved organic matter and its photochemical alteration as revealed by ultrahigh precision mass spectrometry, Limnol. Oceanogr., 55, 1467-1477, 2010.

Stubbins, A., Law, C. S., Uher, G., and Upstill-Goddard, R. C.: Carbon monoxide apparent quantum yields and photoproduction in the Tyne estuary, Biogeosciences, 8, 703-713, 2011, http://www.biogeosciences.net/8/703/2011/.
Stubbins, A., Hood, E., Raymond, P. A., Aiken, G. R., Sleighter, R. L., Hernes, P. J., Butman, D., Hatcher, P. G., Striegl, R. G., Schuster, P., Abdulla, H. A. N., Vermilyea, A. W., Scott, D. T., and Spencer, R. G. M.: Anthropogenic aerosols as a source of ancient dissolved organic matter to glaciers, Nat. Geosci., 5, 198201, doi:10.1038/NGEO1403, 2012.

Vähätalo, A. V. and Wetzel, R. G.: Photochemical and microbial decomposition of chromophoric dissolved organic matter during long (months-years) exposures, Mar. Chem., 89, 313-326, 2004.

Vähätalo, A. V., Salonen, K., Salkinoja-Salonen, M., and Hatakka, A.: Photochemical mineralisation of synthetic lignin in lake water indicates rapid turnover of aromatic organic matter under solar radiation, Biodegradation, 10, 415-420, 1999.

Yamashita, Y. and Tanoue, E.: In situ production of chromophoric dissolved organic matter in coastal environments, Geophys. Res. Lett., 31, L24302, doi:10.1029/2004GL019734, 2004.

Ziolkowski, L. A. and Druffel, E. R. M.: Aged black carbon identified in marine dissolved organic carbon, Geophys. Res. Lett., 37, L16601, doi:10.1029/2010GL043963, 2010. 